\title{
Vocational Tracking and Its Relationship With System Connectivity in the Context of Lifelong Learning (LLL)*
}

\author{
Pham Do Nhat Tien \\ National Institute of Education Management, Hanoi, Vietnam \\ Do Thi Bich Loan \\ National Institute of Educational Sciences, Hanoi, Vietnam
}

\begin{abstract}
There have been many research projects in finding solutions for an effective vocational tracking in Vietnam education. Many comprehensive, system-wide, and multi-disciplinary solutions have been proposed. However, until now, there has been almost no significant change in the tracking after middle and high school. This article assumes that there is a bottleneck that needs to be identified and analyzed thoroughly. From international research and experience, the bottleneck is that tracking has not been yet closely linked to system connectivity and both have not been embedded in the new context of lifelong learning (LLL) development. With this view, the paper proposed priority solutions to promote the implementation of the National Qualifications Framework and soon realize the policy of moving Vietnam education system to an open education system.
\end{abstract}

Keywords: vocational tracking, system connectivity, lifelong learning (LLL), national qualifications framework, open education

\section{Introduction}

How to implement vocational tracking effectively is an issue that has already promoted many research projects in Vietnam in view of finding reliable solutions. Based on the research findings, the Government Decree No. 75, issued on August 2, 2006, had the following provisions for the implementation of vocational tracking:

1. The Ministry of Education and Training is responsible for career guidance education to prepare students before tracking;

2. The Ministry of Planning and Investment shall guide ministries and provincial-level People's Committees to forecast the human resources structure in terms of professional qualifications and occupations in the socio-economic development planning of the country, each sector and locality;

3. The People's Committees at all levels shall have to forecast and publicize the demand for human resources in the annual and five-year plans of the localities, elaborate specific policies aimed at linking training to employment, and direct local educational management agencies to carry out tracking with quality and

\footnotetext{
* Acknowledgement: The article of the study was conducted within the framework of the research project KHGD/16-20.ĐT.002 funded by the National Program on Science and Technology for the period 2016-2020.

Pham Do Nhat Tien, D.Sc., senior researcher, Scientific Council, National Institute of Education Management.

Do Thi Bich Loan, Ph.D., associate professor, senior researcher, Research Division of Educational Policies and Strategies, National Institute of Educational Sciences.
} 
efficiency;

4. Universities, colleges, and vocational schools annually publicize their majors and training capacity, take specific measures to use school career guidance results during the enrolment and training process;

5. State agencies, social organizations, professional social organizations, and economic organizations have the responsibility to create opportunities for secondary students to familiarize themselves with their future environment.

It is clear that it was a sound system of solutions to mobilize the participation of related parties to join hands to promote vocational tracking. These solutions were also proved to be relevant and achievable, and therefore, a positive change in tracking could be expected after the implementation of Decree No. 75.

However, it is not the case. The actual vocational tracking in Vietnam remains one of the most pressing issues. The majority of pupils, after completing middle and high schools, used flocking to the general track of education. Vocational education and training (VET) is only the last choice.

The causes to that undesirable situation will be discussed in the next section. However, it is the assumption of this paper that there is a bottleneck in the process of implementation. The identification of that bottleneck and its implications for an effective implementation of vocational tracking will be discussed in the five subsequent sections with some conclusions in the last section.

\section{What Is the Cause?}

There have been many research projects looking for answers. Nguyen Dac Hung (2015) had identified a system of 10 main causes leading to weaknesses in tracking as follows:

1. Incomplete awareness of all parties concerned on the importance of tracking;

2. State policies are not enough to encourage secondary students to take the vocational track and to create favorable conditions for vocational schools to recruit students;

3. Negative impact of the so called "degree-illness" in Vietnam society;

4. Poor labor market information system;

5. Rigid education system with poor connectivity between different levels and tracks of education;

6. Overlapping, inconsistent, and delayed VET management;

7. Inefficient and inappropriate career guidance and counseling in schools;

8. Poor investment by the state and society for VET development;

9. Inappropriate curriculum in VET for students graduating from middle schools;

10. Inadequate distribution of VET institutions, and mismatch in the organization and operation of VET.

Previously, Do Thi Bich Loan (2014) had already come up with a system of similar causes, from the causes related to awareness and career guidance to the causes concerning system structure, VET management, policy incentives, VET quality, and labor market information.

In sum, vocational tracking is not the responsibility of the education sector alone. Its implementation requires an ineterdisciplinary coordination that the provisions of Decree No. 75 already aimed at, but it must also be complemented by a number of other related provisions, such as the raising awareness of stakeholders to the benefits of VET and vocational tracking, incentive policies for students entering the vocational track, etc.

As before-mentioned, the approach of this article is not to find a comprehensive solution for the implementation of vocational tracking. Its approach is based on the assumption that the actual stagnation in vocational tracking is due to a bottleneck in tracking. 
Namely, attention has not yet been paid duly to establish a close relationship between vocational tracking and system connectivity ${ }^{1}$, and to consider both within the context of lifelong learning (LLL). The rationale for this statement is clarified in the section below.

\section{Vocational Tracking and System Connectivity in the Context of LLL}

In a study based on the system assessment and benchmarking for education results (SABER) approach, Patrinos (2012) analyzed tracking in Europe and East Asia which seemed to show that an effective tracking policy needed to reduce early tracking and ensure system connectivity, so that students were allowed to switch back and forth between tracks and levels of education. The rationale for connectivity is quite simple: If the tracking is really ensured by system connectivity, then students pursuing VET will no longer feel that they are within an impasse, but can continue to study at higher levels or change the pathways when needed.

However, that is just one aspect of the problem. In fact, VET today in particular, and skills development for learners in general, should be considered in the context of LLL. In other words, although tracking is a stage at the end of middle or high school, it is closely related to all stages and forms of learning in the LLL system.

To have an insight of vocational tracking within a comprehensive system of skills development for learners throughout their lifecycles, it is useful to refer to the skills toward employment and productivity (STEP) framework developed by the World Bank (2010).

The STEP framework consists of five interlinked steps: From "Low" (Step 1) to "High" (Step 5), on the journey to improve skills:

Step 1. Getting children off to the right start;

Step 2. Ensuring that all students learn;

Step 3. Building job-relevant skills that employers demand;

Step 4. Encouraging entrepreneurship and innovation;

Step 5. Matching the supply of skills with the demand.

The implementation of these steps involves many sectors, including education and training, labor and employment, social protection, and economic policy. It also extends throughout life and across generations, including today's children, workers, and youth who could be tomorrow' skilled workers. The framework is expressed as a consistent system of step-by-step programs to improve skills throughout life, and as such vocational tracking can be considered as a transition stage from Step 2 to Step 3. Thus, the effectiveness of vocational tracking depends on the preparation of basic social skills, cognitive skills, and behavioral skills in Steps 1 and 2, as well as the quality of the training programs in Step 3, including Steps 4 and 5. In other words, the effectiveness of vocational tracking requires a holistic approach from the viewpoint of LLL, which means that there is a need for good preparation of the necessary skills before tracking and the continuation of skills development after tracking in view of creating opportunities, conditions, and motivations for workers to improve their qualifications or change their occupations according to their specific requirements, interests, capabilities, and conditions.

\section{Vocational Tracking in Vietnam Education From the View of Connectivity and LLL}

Strictly speaking, in the context of international integration, Vietnam education system has been restructured to be compatible with advanced education systems in the world according to the International

\footnotetext{
${ }^{1}$ In this article, system connectivity means the flexibility of the education system in allowing students to switch back and forth between tracks and levels of education.
} 
Standard Classification of Education (ISCED) (UNESCO-UIS, 2011). Studies showed that, in terms of system structure, Vietnam education system has been designed and restructured in a way that facilitates tracking, connectivity and LLL (Vu, Nguyen, Dang, \& Pham, 2013).

However, in terms of operating mechanism, all three mechanisms in tracking, connectivity, and LLL do not operate properly and do not support each other.

The weakness of the tracking mechanism has been pointed out from the beginning of this article. As for connectivity, the openness in policy coupled with the weakness in management have led to a complex and distorted picture: Internal connectivity within each training institution has been profited to increase enrolment on the one hand, and enable weak students to easily climb to higher education with unsecured quality on the other hand. Cross connectivity between training institutions are either a form of being in cahoots with each other or rhetoric, because there is not any tool for institutions to recognize or to trust the quality of each other.

As for putting vocational tracking in the context of LLL according to the above-mentioned STEP framework, the Vietnam Development Report 2014 (World Bank, 2013) showed that economic growth and restructuring were leading to the shift of jobs and skills from predominantly manual and routine tasks towards more analytical, interactive, and non-manual tasks. Yet, education was not renovated adequately and equipped sufficiently to respond. Thereby, the unsuccessful implementation of vocational tracking might be attributed to the shortcomings in different steps of the STEP framework. Namely, in Step 1, the support for the development of children aged 0-3 and quality preschool for children aged 3-6 remain weak; in Step 2, more schooling for all and better schooling for all are needed; in Steps 3, 4, and 5, the skill development system is suffering from disconnects between employers and students and universities, colleges, and vocational schools. In summary, even though Vietnam education has made great efforts and progress in the development of a LLL system, but facing the requirements of the STEP framework, that LLL system was still an unresponsive system, incapable to create an effective mechanism linking training to employment, so as workers were able to develop their skills throughout life.

The problem is that it is necessary to introduce into the education system an operating mechanism to create a close relationship between tracking and connectivity on the one hand, and to embed both within the framework of building a LLL system on the principle of linking training to employment on the other hand. The solution of this problem can be found in the context of today education development and practice. It is an operating mechanism based on the design and implementation of the National Qualifications Framework (NQF).

\section{Impacts of NQF on Tracking, Connectivity, and LLL}

In fact, how to link training to employment is a complex problem, annoying but pressing of all education systems in the world, especially in the actual context of a volatile and unpredictable labor market. However, the close cooperation and collaboration in the last years of the 20th century between the education sectors with the world of work has led to the creation of a tool that is considered to be effective in creating linkage between training and employment. That is the NQF.

NQFs have been, during the last two decades, considered as the key instruments for the restructuring and reform of education, training, and qualifications systems in the world. NQFs were developed in accordance with the trends of linking training to employment and enabling LLL in human resources development. NQFs focus on learning outcomes and recognize learning outcomes from all forms of learning, formal, non-formal, and informal. As such, NQFs become transparency tools whose main tasks is to clarify the relations, vertically 
between different levels of education during the LLL journey, and horizontally between learning outcomes and demands of the labor market.

The importance of NQFs has been analyzed in a rich body of literature. However, in the scope of this article concerning the impact of NQFs on tracking, connectivity, and LLL, the following benefits are identified from practical experiences of NQFs implementation in many countries (Cedefop, 2018; Singh \& Duvecot, 2013):

1. NQFs enhance the domestic and international transparency of the education system, creating sound basis for recognition, validation, and accreditation (RVA) of learning;

2. NQFs strengthen the practicality and effectiveness of the education system, facilitating learners in employability and employers in recruitment;

3. NQFs enhance the image of VET and bridge the divide between VET and higher education, promoting tracking in the education system;

4. NQFs enable learners to progress both vertically and horizontally on the basis of their competencies, thus facilitate connectivity and promote LLL.

In sum, the dominant advantage of the NQFs has been to remove some barriers related to awareness in vocational tracking, to RVA of learning in system connectivity, to motivations in LLL, and to the transparency of the qualifications for employers.

However, there are still some important barriers to access to LLL, especially quality education. They are financial barrier (related to tuition fees and expenses for materials and textbooks), geographical barrier (related to learners in remote areas), and time barrier (related to working hours). Therefore, besides NQFs development, another step has been taken in the past two decades to remove those barriers. That is the introduction of open education.

\section{Open Education and LLL}

Open education is a new approach to education development with the basic purpose to remove unnecessary barriers, so as the right to education becomes truly one of the basic human rights. It is closely linked to LLL but not LLL.

While LLL aims to expand education in terms of time and space, open education is concerned with removing unnecessary barriers to access to education. Thus, open education is an important move in education to translate LLL from rhetoric to reality.

It can be considered that the opening of the UK Open University in 1969 and subsequent series of open universities around the world was the first step of open education with the removal of barriers in recruitment policies and quotas. However, open education has only really been a breakthrough in the past 17 years, since the Massachusetts Institute of Technology (MIT) posted open courseware in 2002, followed by an explosion of open educational resources (OER) and massive open online courses (MOOC), enabling people to access quality education for free anytime and anywhere.

At the macro level, the roles as change agent of open education in general, OER and MOOC in particular, may be considered in three aspects: Firstly, by overcoming the barriers of traditional face-to-face learning in a concrete space-time, open education is a breakthrough solution to realize the LLL policy for all; secondly, owing to the flexibility of the program and its possibility to "tailor" according to individual learners' needs, open education is a big step in personalizing education; and thirdly, by providing at low or no cost, open education reinforces the view that education is a public good and create opportunities to "abandon a free-market approach 
to education in favor of collaborating to build and share knowledge” (Kanwar \& Uvalic-Trumbic, 2011, p. 35).

Particularly, for open VET, the removal of barriers to facilitate learners to improve their skills throughout life is implemented in a variety of ways, including open to people, open to place, open to time, open to curriculum, open to ideas, open to methods, open to training institutions, and open to resources (Doan, 2018; Pham, 2018).

So, the embedding of vocational tracking into open education in general, open VET in particular, is another breakthrough to dismantle financial, geographical, and time barriers, thus creating conditions for learners who have pursued the vocational track to have in front of them enormous LLL opportunities free of charge, anytime, anywhere, and every way.

In this respect, it is worth mentioning here a success story which is the Sills Future initiative developed by the Ministry of Manpower in Singapore. Singapore is well known for its success in tracking even though the tracking is done early, right after primary school graduation. In many lessons learned, is a lesson of linking tracking with connectivity in a context of LLL (Driskell, 2018). The operating mechanism is based on a well-functioning NQF coupled with an open education which is designed and developed according to the Sills Future initiative, focusing on moving towards an economy where individuals seek LLL within their areas of expertise to stay relevant and ready for the future.

\section{Bottleneck in Vietnam Vocational Tracking}

As before-mentioned, the Vietnam education system has already been restructured, so as tracking, connectivity, and LLL are enabled. What is lacking is an operating mechanism based on a good implementation of a NQF and open education. That is the very bottleneck in Vietnam tracking which policy makers need to have a thorough identification and sound analysis.

In fact, in terms of policy, both NQF development and open education introduction have been mentioned in the Education Development Strategy 2011-2020. Since then, some moves can be identified as follows:

1. About open education, the Party Central Committee Resolution No. 29, issued on November 4, 2013, has officially prescribed one of the nine tasks for a fundamental and comprehensive renovation of education was to improve the education system towards open education, LLL, and building a learning society. This policy is actually institutionalized in the draft of the revised Education Law. Two national workshops on open education and open VET were respectively held in 2018 by the Association of Colleges and Universities and the VET Association. That is all. The concept of "open” still largely stops on text and some academic exchanges.

2. About NQF, the Vietnam NQF has been issued under Prime Minister Decision No. 1982 on October 18, 2016. The purpose of this NQF was to link training to employment, create connectivity among training levels, and build a LLL society. However, it is still only a conceptual framework with eight qualifications described basically by corresponding learning outcomes. In order for this NQF to reach the desired goal of paving the way for tracking, connectivity, and LLL, it is necessary to go on developing a consolidated conceptual framework towards the implementation of NQF.

In this respect, it has already been stipulated in Decision No. 1982 that the Ministry of Education and Training and the Ministry of Labor, War Invalids, and Social Affairs shall have, within their authority, the responsibilities as follows:

1. To deliver NQFs according to the levels of education and training under their authority, elaborate plans, 
necessary conditions, and roadmap for implementation and submit them to the Prime Minister for consideration and approval;

2. To preside and coordinate with related ministries, professional associations, educational institutions, and research institutes to develop and approve the learning outcomes for each qualification in each sector and field of training;

3. To direct education and training institutions to review, amend, and improve their curriculum in accordance with approved learning outcomes, and towards submission for quality accreditation.

Obviously, all that required considerable time and resources to be established. However, it is noteworthy that until now there is not any step in the implementation of the above-mentioned stipulations, and thus the Vietnam NQF remains chiefly on paper.

Therefore, the stagnation of Vietnam vocational training is due chiefly to the stagnation in the implementation of the NQF and open education policy.

\section{Conclusions}

From the above discussion, the following conclusions can be made.

Putting vocational tracking within the overall problem of human resources development in the context of LLL, previous studies of Do (2014), Pham (2014), and Nguyen (2015) have provided, in one form or another, complementary systems of solutions for a long-term, sustainable, and holistic implementation of vocational tracking, including pre-tracking, in-tracking, and post-tracking.

However, the implementation of a comprehensive system of solutions cannot be deployed all at the same time but requires the identification and selection of priority solutions.

It is namely in that direction, Prime Minister Decision No. 522 has been issued on May 14, 2018, giving priority to quality improvement in secondary school career guidance. This might be seen as a priority solution before tracking.

However, according to this article analysis, the very bottleneck in Vietnam tracking resides chiefly in a poor relationship between tracking and connectivity as well as an inadequate implementation in LLL. All this is due to the absence of an operating mechanism based on the implementation of a NQF and open education.

Therefore, besides the above-mentioned priority solution before tracking, it is necessary to complement it with priority solutions in-tracking and post-tracking. That is the development and implementation of the Vietnam NQF coupled with a step-by-step improvement of the education system towards open education.

By that way, after receiving quality career guidance, students are assured to enter the vocational track with a relaxed psychology and belief that it is the same pathway as every other pathway, leading to an open and broad horizon in career development.

\section{References}

Cedefop. (2018). Analysis and overview of NQF level descriptors in European countries. Luxembourg: Publications Office. Cedefop research paper No. 66. Retrieved from http://data.europa.eu/doi/10.2801/566217

Do, T. B. L. (2014). Solutions for vocational tracking and connectivity in the education system. In V. K. Phan (Ed.), Vietnam education management innovation: Some theoretical and practical issues (pp. 129-210). Hanoi: Hanoi National University Publishing House. (in Vietnamese)

Doan, M. D. (2018). Development of an open and flexible vocational education system, creating opportunities for workers to train, to be employable and to have sustainable jobs. In Workshop Proceedings: Development of an open and flexible vocational education system, creating opportunities for workers to train, to be employable and to have sustainable jobs. Hanoi, Vietnam. 
Kanwar, A., \& Uvalic-Trumbic, S. (Eds.) (2011). A basic guide to open educational resources (OER). Vancouver: Commonwealth of Learning; Parris: UNESCO.

Driskell, N. (2018). Streaming in Singapore: It's not tracking, and it actually promotes equity. Retrieved from http://ncee.org/2016/12/streaming-in-singapore/

Nguyen, D. H. (Feb. 13, 2015). Solutions for the promotion of vocational tracking after middle and high schools. Final report of the research project CB2014-04-35BS, presented to the Review Council at the Institute of VET sciences. (in Vietnamese)

Patrinos, H. A. (2012). Vocational tracking. In H. A. Patrinos (Ed.), Strengthening education quality in East Asia (pp. 85-96). Paris: UNESCO \& The World Bank.

Pham, D. N. T. (2014). Solving the tracking problem in Vietnam education from the perspective of building a learning society. Education management journal, 62(7), 1-5. (in Vietnamese)

Pham, T. D. (September, 2018). Building an open vocational education system in a learning society. In Workshop Proceedings: Development of an open and flexible vocational education system, creating opportunities for workers to train, to be employable and to have sustainable jobs. Hanoi, Vietnam.

Singh, M., \& Duvekot, R. (Eds.). (2013). Linking recognition practices and National Qualifications Framework. Hamburg, Germany: UNESCO Institute for Lifelong Learning.

UNESCO \& COL. (2011). A basic guide to open educational resources. Paris: UNESCO and Vancouver: COL.

UNESCO-UIS. (2012). International Standard Classification of Education. Montreal, Canada: UNESCO Institute for Statistics.

Vu, N. H., Nguyen, M. D,. Dang, B. L., \& Pham, D. N. T. (2013). Governance of Vietnam education system in fundamental, comprehensive renovation and international integration. Hanoi, Vietnam: Vietnam Education Publishing House. (in Vietnamese)

World Bank. (2010). Stepping up skills for more jobs and higher productivity. Washington DC: The International Bank for Reconstruction and Development.

World Bank. (2013). Vietnam Development Report 2014. Hanoi, Vietnam: Vietnam Development Information Center. 